\title{
Studies on the Influence of Chinese Consumer's Irrational Consumer Psychology on Their Consuming Behavior
}

\author{
Hai-Xia ZHANG \\ ${ }^{1}$ Management Faculty of Harbin Finance University, Harbin, PR China \\ azhanghaixiagg@163.com
}

\begin{abstract}
Keywords: Irrational consumption, Conspicuous consumption, "Keeping up with the Joneses" consumption, Impulsive consumption
\end{abstract}

\begin{abstract}
As China is in the transitional period under the historical background currently, there is a great change in Chinese's consumption level and consumption structure, which leads to some problematic consuming behavior in Chinese consumer market. The problematic behavior manifests as some irrational consuming behaviors and these consumption characteristics show an evident increasing trend. Aiming at these characteristics, this paper puts forward a series of thinking for reducing irrational consumption such as purifying social environment and constructing a harmonious consumption environment, advocating civilized consumption concept and strengthening consumption moral construction, guiding and standardizing consuming behavior.

With the deepening of reform and opening up, China has realized all-round social transformation and the people's material and cultural life has turned around completely. Contemporary China has already been characterized with a consumer society in many respects. People's consumer psychology, consumption structure, consumption concept and consuming behavior are changing significantly. Consumption is no longer just the result of production and circulation. It becomes more and more independent and plays an increasingly important role in maintaining social stability, stimulating the economy, boosting domestic demand, promoting social development and constructing personality.
\end{abstract}

\section{Analysis of Chinese Consumer's Consumption Status}

\section{Significant Increase of Consumption Level}

After the reform and opening up, the rapid growth in the income of Chinese resident has stimulated significant increase in consumption level. According to China's National Bureau of Statistics, in 2015, per capita consumption expenditure of Chinese resident was 15,712 yuan, an increase of $8.4 \%$ over 2014 , or a real growth of $6.9 \%$ after deducting price factors. Compared with 1978, the per capita consumption expenditure in 2015 increased 49.52 times. The popularity of modern living facilities has further increased and according to China's Internet Industry Overview 2015 and Trends Report 2016 released by the Internet Society of China, China's Internet penetration rate will exceed $50 \%$ in 2016. The economic performance of communication industry in October, 2015 released by Supervision and Coordination Bureau of Economic Operations of MIIT shows that the mobile phone penetration rate in China has reached 95 phones per hundred people and the rate in Beijing has reached 193.7 phones per hundred people.

\section{The Growth Rate of Consumption is Higher than GDP in China}

From 2011 to 2015, the growth rate of China's total retail sales of consumer goods exceeded GDP growth rate every year. In 2015, China's total retail sales of consumer goods passed 30 trillion yuan mark (as in Table 1), a real growth of $10.7 \%$ after deducting price factors. The total retail sales each year even may underestimate the consumption situation for not including some service consumption which has increased rapidly in recent years, such as expenditure related to education, housing, health care. From table 1 we can see that the growth rate of China's total retail sales of consumer goods is significantly higher than GDP growth rate in recent 5 years. 
Table 1 Total Retail Sales of Consumer Goods and Total GDP in 2011-2015

\begin{tabular}{|c|c|c|c|c|c|}
\hline Year & 2011 & 2012 & 2013 & 2014 & 2015 \\
\hline $\begin{array}{c}\text { Total retail sales of consumer goods } \\
\text { (hundred million yuan) }\end{array}$ & 187206 & 214433 & 242843 & 271896 & 300931 \\
\hline $\begin{array}{c}\text { Year-on-year growth of total retail sales } \\
\text { of consumer goods (\%) }\end{array}$ & 21.1 & 14.6 & 13.2 & 12.0 & 10.7 \\
\hline Total GDP (hundred million yuan) & 484123 & 534123 & 588018 & 635910 & 676708 \\
\hline GDP year-on-year growth (\%) & 9.2 & 7.8 & 7.7 & 7.4 & 6.9 \\
\hline
\end{tabular}

Data source: National Bureau of Statistics

\section{Gradually Optimized and Reasonable Consumption Structure}

As the consumption level has been constantly improved, the consuming stratums are rising, the consumption scope is expanding and the consumption structure is becoming more and more reasonable. The consumption needs a transition from meeting material needs like survival needs and security needs to meeting spiritual needs like social needs, respect needs and the need of self-fulfillment; a development from living type consumption purely concerning food and clothing to diversified development type consumption related to food, residence, education, medical care, transportation, communication, culture and so on; a change from material consumption to service consumption such as health care, education, finance and insurance, leisure tourism, sports and cultural mass media; an upgrade from traditional consumption to personalized and diversified new consumption; the trend of this upgrade is becoming more and more apparent and the speed of it is increasingly fast. New consumption hotspots such as culture, transportation, education, communication, medical treatment, health care and tourism have gradually emerged.

\section{Personality Consumption is Highlighted and the Luxury Market has Developed Rapidly}

In recent years, pursuing fashion, individuality and self-expression has gradually become the main consumption feature of the new generation consumers, which is concretely showed in the phenomenon that consumers are increasingly seeking individualized consumption and try to show individuality through brands. They mainly pursue the symbolic meaning of commodities and the self-fulfillment while purchasing merchandise, package themselves with personalized and fashionable style, and stand to society in the relation of their distinctive personal image, temperament, charm and grace. It is common consumer psychology of consumers today to be lined with the times and keep up to date, which is the typical performance of people's social psychological need in the consumer sector.

In the last decade, the luxury market at a global scale has being withering away while the luxury consumption in China has been growing rapidly. In 2013, China accounted for $47 \%$ of global spending on luxury goods. In 2014, China's consumption of luxury goods amounted to around 380 billion yuan and in 2015 the consumption amounted to around 758.45 billion yuan. The contribution of Chinese consumers to the luxury industry increased from 1.4\% in 2005 to $46 \%$ in 2015 in the past decade. According to the study of Chinese Brand Strategy Associates, so far, China's luxury consumers have reached $13 \%$ of the total population. And a report of BNP Paribas Peregrine says that China has entered the growing stage of luxury consumption.

\section{Main Problems of the Consumer Behavior in Chinese Society}

\section{A Wave of “Conspicuous” Consumption Unleashed by the Loss of Consuming Moral}

With the rapid development of socialist market economy and progressive improvement of consumption level, extravagant, worthless and excessive "conspicuous" consumption is gaining steam in China. Consumption has huge attraction and stimulus for consumers which result in endless expansion of consumers' purchasing desire. As mentioned in Consumer Society written by French sociologist Jean Baudrillard in 1970, the purpose of this kind of consumption is not to meet actual needs but to constantly pursue the satisfaction of desire that has been created and stimulated. 
So, some customers purchase goods not for their value in use but for possessing them and hence a special consuming behavior that people pursue consumption for its own sake has emerged. Current consuming behavior in Chinese society will inevitably lead to enormous waste to natural resources and further degradation of eco-environment. The unending exploitation by human beings for material goods has seriously threatened the ecological balance of the whole society.

\section{Loss of Purposefulness Dimension}

Consumption is a means of people to achieve happiness and should be positive, humanistic and creative experience. However in the current Chinese society, consumption becomes the satisfaction of fantasy created by artificial stimulus and becomes an end in itself. While people consume in an uncontrolled manner, their main purpose is to show off their wealth, status and identity. So in fact, this kind of consumption has become the symbol of social superiority to stir up people's envy, respect and jealousy. As Fromm said, "in face of various material temptations, modern people focus on material pursue without hesitation and they believe that they will attain happiness as long as they possess wealth, but the case is just the reverse and the more they are occupied, the more they suffer from solitude"[1].

\section{Irrational Consuming Behavior like Conspicuous Consumption, "Keeping up with the Joneses” Consumption and Impulsive Consumption}

Irrational consuming behavior refers to the behavior that when people directly or indirectly purchase, use commodities or accept service based on consuming needs, they lack reasonable grounds subjectively or objectively and this lead to negative social influence. The main manifestations of consumers' irrational consuming behavior include: legal in form but actually irrational consuming behavior; legal in form but actually illegal consuming behavior; illegal consuming behavior. This paper carries on the elaboration based on "legal in form but actually irrational consuming behavior". In the transitional period of contemporary Chinese society under the historical background, some notable features have emerged in Chinese consuming market: conspicuous consumption, "keeping up with the Joneses" consumption and impulsive consumption. These consuming characteristics are bound to cause consuming behavior to have irrational features and this situation shows an upward trend.

\section{The Impact of Irrational Consumer Psychology on Chinese Consumer Behavior \\ Main Manifestations of Irrational Consumer Psychology}

Rational consumption means under specific consumption environment, the consumer evaluates possible outcome of the consuming behavior and then make the choice to seek maximum customer delivered value. Irrational consumption means the consumer does not have a clear understanding of his or her own needs and fails to rationally determine consumption level, consumption structure and consumption patterns. It is shown as excessive spending in spite of personal income or finance, and consumption lacking social responsibility. Irrational consumption includes conspicuous consumption, "keeping up with the Joneses" consumption, symbol consumption, impulsive consumption, mood consumption, human consumption, ignorant consumption, consumption not saving energy and protecting the environment, and any other consumption lacking social responsibility.

\section{Main Reasons for Irrational Consumer Psychology}

\section{Impact of "Materialistic" Culture in the Society}

Culture is the most direct and underlying factor affecting consumer purchase behavior. With the improvement of people's material conditions, the traditional consumption concept "thrift" has met with enormous impacts and challenges. New "consumption first" and "materialistic" consumption concept has taken into shape. This concept plays a guiding and controlling role in people's consumer psychology, lifestyle, values and consuming behavior. Dazzling commodities are like the 
cave of Ali Baba and become the engine triggering consumption desire. Some people even intend to sell a kidney for buying a new iphone. Excessive, competitive, extravagant and conspicuous consumption pushes our life forward and not only makes people lack detachment in face of gaining and losing material things, but also leads them to house slaves, car slaves and card slaves "road to servitude". In the eyes of some people, the consumption and acquisition of material goods are the only sign of their ability, the ultimate symbol of success, the concentrated reflection of social status and the only support of the spiritual life [2].

\section{Overcompensating the Poverty Complex in Subconscious Mind}

In recent history, China is closely combined with poverty and backwardness. Poverty has always plagued the mental world of Chinese people and caused the formation of poverty complex in their subconscious mind. In October 23, 1985, Deng Xiaoping met with a delegation including senior American entrepreneurs and said: "Some regions and some people may prosper before others do, and then they can help other regions and people to gradually do the same”. Reform and opening up opened the door for Chinese people to achieve prosperity. Some people have amassed great sums of wealth through various ways and after lifting themselves from miserable lives, they are eager to live an honorable life with dignity and status. Years of pent-up poverty complex is reflected in an almost crazy way_conspicuous and freakish consuming behavior, which is an overcompensation phenomenon according to Jungian psychology. Overcompensation means one nuclear complex is obscured by another complex which temporarily has stronger mental energy. The reason that this complex has stronger mental energy is because people deliberately transfer their "mental energy" from "real" complex to "feigned" complex [3]. From this observes, spendthrift explicit consuming behavior is deeply penetrated with a high-level fear of poverty in their subconscious mind. Or we can say the mental energy of years of pent-up poverty complex in their subconscious mind is completely released through this way.

\section{The Exaggeration of the Media Induces the Purchasing Behavior of Consumers}

The media plays an invisible but powerful controlling and guiding role in modern people's consumer psychology, life attitude, value orientation and behavior custom. In the past, most Chinese consumers purchased goods for their value in use, which reflects an "active" consuming behavior. However, with the increases in purchasing power, especially the prevalence of the mass media, consumers' behavior has gradually changed from "active" consumption to "passive" consumption. "Journalists and advertisers are all magic manipulators: they direct and invent items and events". The advertising media "targets all consumers through each consumer and also targets each consumer through all consumers" [4]. Consumers are controlled by consumption and manufacturers. Driven by profit maximization, manufacturers continually expand reproduction and induce consumers through advertising media, and hence exert huge impact and attraction on consumers' psychology. And therefore consumers are willing to accept and submit to this kind of manipulation and control as they are satisfied with the "happy" feeling and the fulfillment of desires. As Fromm points out: "consumption is essentially the satisfaction of fantasy created by artificial stimulus and it is an illusory activity which is different from our true ego.[5]"

\section{Confuse High-Level Consumption with “Conspicuous Consumption”}

The connotation of high-level consumption is more reasonable consumption structure, improved consumptive level, more varied consumption types and growing consumption quantity. The basic rule in the modern society is "survival of the fittest" and hence competition is naturally an important content in people's life. Psychoanalyst Horney believes that: "the competition taking economy as central radiates into all activities and permeates love, social relations and games." To show off the superiority and to remind the world of their existence, many people compete with others by various means at all levels. As a phenomenon most commonly occurs in everyday life and also one of comprehensive ways reflecting people's ability in the economic society, consumption is madly pursued by some people as the most intuitive and most comparable competition index. It should go without saying that the amount of money people spend in high-level consumption increases 
significantly, but this is completely different from extravagance and waste. We believe that the essential difference between high-level consumption and extravagance is not the amount of money people spend, but whether the consumption is scientific and reasonable, whether it meets rational material and spiritual needs, and whether it matches with their income.

\section{The Influence of Chinese Consumer's Irrational Consumer Psychology on Their Consuming Behavior}

\section{Endless Conspicuous Consumption, “Keeping up with the Joneses" Consumption and Symbolic Consumption}

Like the old saying goes "adversity leads to prosperity", many people had no social status in the past and was not respected and taken seriously by the society, therefore they show their personal values in certain ways after success to gain the recognition and appreciation of society. As a result, it is the initial and natural choice to convey information about self-identity, wealth and status by purchasing and using scarce and expensive commodities that have excellent quality. Hence conspicuous consumption, "keeping up with the Joneses" consumption and symbolic consumption have emerged.

Veblen puts forward the famous "conspicuous consumption" theory in Theory of Leisure Class (1983) and believes that "Extravagant and unnecessary consumption are essential for effectively increasing consumers' honors. Waste is necessary for gaining a good reputation.” The purpose of people's conspicuous consumption is to show their noble status and special social class and they take consumption as the symbol of wealth. However, few people are acquainted with the culture and taste carried by these consumer goods.

The word "comparison" is nothing new to most Chinese people. It is generally acknowledged that "comparison" refers to the psychological pattern that individuals compare their situation with people who have similar experiences as themselves or with their ideal situation to obtain psychological balance. In recent years, with the prevalence of extravagance, the comparison phenomenon is showing a growing trend and the largest component is the young people. The data survey and analysis indicate that: in Chinese mainland, luxury consumption came from $13 \%$ of the total population and most consumers are young people under the age of 40. "Keeping up with the Joneses" consumers don't consider their needs and purchasing power. The main factor affecting their consuming behavior is often "economic and social behavior of other people who are in the same class as themselves”.

Consumers change the using concept of people towards material goods in the past. Commodities' use value has become faded-out gradually and what replaces it is the symbol value of consumption. The pursuit of symbolic meaning is pursuing desire itself and is an endless consumption process. The behavior style driven by this consumption process is the typical consumerism lifestyle. As Jean Baudrillard said, "The logic of commodity has been universal and not only dominates labor process and material products today, but also dominates the whole culture, sexuality, human relations, phantom and impulsion of individuals., ${ }^{[6]}$ Thus, people pursue consumption for its own sake and greedily devour one commodity symbol after another. There will be no restriction, no end, and no full satisfaction.

\section{Impulsive Consumption and Mood Consumption Have Emerged}

As the pace of life continues to increase, people began to have a serious blundering psychology in a world of mundane pursuits. The behaviors of impulsive consumption are getting worse by the day while on the contrary, behaviors of rational consumption are decreasing day by day. When judging things, lacking of concept is the inevitable result for this phenomenon. Replacing reason with emotion and lack of thoughts before action are features of impulsive consumption. People often make snap decisions when they are impulsive or impetuous and regret immediately after the purchase. Plenty of commodities are abandoned after very little use. This impulsive consumption model has made up a sizable portion of overall consumption.

People in an unstable mood are prone to generate impulse purchasing desire and this impulsion 
results in consumers' actual consuming behavior when they are lacking knowledge of the commodity. Mood consumption is more commonly seen in female consumers. According to the independent polling company, a startling number of women purchase due to extreme emotions and the percentage is closer to $46.1 \%$. When women are in a bad mood, shopping is a way for them to relieve stress, balance emotions and ease the sense of helplessness. And when they are happy, shopping is also a way for them to express pleasure. Emotional women get a lot of satisfaction required by self-improvement from perceptual consumption and the emotional balance between needs and actual purchasing power is realized, which makes mood consumption become more and more frequent.

\section{Increasingly Intensive Human Consumption and Ignorant Consumption}

Human consumption refers to gift exchange, exchange of monetary gift and potluck in human interaction for saving face. Chinese society is a society of human relationship. Taiwanese scholar Huang Guangguo points out that "human relationship refers to a resource which can be given to each other as a gift in social transaction and also refers to the social regulation about how to interact with each other in Chinese society." Today, it's common to see people tighten their belt or even borrow money for repaying the debt of gratitude and this phenomenon shows an upward trend. The key feature of ignorant consumption is spending money to satisfy some imaginary sustenance instead of meeting rational and realistic material and spiritual needs. So far, one of the most prominent phenomena of ignorant consumption is "white consumption", which means the consumption related to superstitious activities such as extravagant bereavement, building tombs, setting Taoist rites, burning fake objects, even collectively building "idol temples". This abnormal consuming pattern is especially relevant in the social group with lower education level.

\section{Rational Guidance of Chinese Consumers' Irrational Consumer Psychology}

\section{Purify Social Environment and Construct Harmonious Consumption}

Externally, supervision and guidance of consumption should be strengthened and it is very important to create a good social consumption environment. Outlook on life, value and good social custom fitting with the demands of modern society and adapting to operation model of socialist market economy and corresponding strengthening mechanism should be established in the society. A new cast of healthy and in-deified role models adapting to the requirement of modern times should be reset for people to learn from. Undoubtedly, this is a very hard systematic task but its practical significance and historical significance will be invaluable.

Internally, it is crucial to develop the moral quality, consumption consciousness and consumption morality and ethic of consumption subject. Harmonious consumption requires the intercoordination and harmonious operation of the consumption subject among factors constituting the consuming behavior (including consumption subject, consumption object, the external environment of consumption, etc) during the process of consumption. Harmonious consumption contains external harmony and internal harmony. Internal harmonious consumption mainly refers to factors restricting consuming satisfaction among consumption subjects which include the harmony and unity among consuming quality (balance between material and spiritual consumption), appropriateness of consumption (undesirability of excessive consumption and inadequate consumption), consumption structure (rural-urban consumption structure differences) and consumption notion (civilized and scientific consumption concept). External harmonious consumption mainly refers to: harmony between man and consumption environment, harmony between man and national economic development and mutual harmony among consumption subjects. Specifically, external harmonious consumption means moderate consumption, protecting the environment, saving energy, protecting animals, supervising enterprises and safeguarding civil rights, supporting enterprises' responsible conduct, resisting enterprises' irresponsible conduct, supporting middle and small-sized enterprises, supporting native goods, and so on. 


\section{Advocate Civilized Consumption Concept and Strengthen Consumption Moral Construction}

Advocating rational and civilized consumption concept means sticking to moderate consumption pattern and arranging consumption structure reasonably step by step according to consumption needs from not required consumption to highly required consumption. In microcosm, each consumer should improve their consumption accomplishment and resist vain, competitive and vulgar consuming value idea to make people's consuming behavior and consumption concept be more scientific and reasonable. Advocating rational consumption concept is a resistance to "consumption alienation" and a negation of consumerist values. It emphasizes the premise of human existence and development during the consuming behavior and encourages healthy, civilized, and sustainable consumption pattern. The essence of consumption followed by it is the humanity concept.

\section{Guide and Standardize Consuming Behavior and Pave a Healthy Way for Rational Consumption}

Education of consuming can be carried out from two aspects: education of correct consumption views and education of consumption technology. Official, highly authoritative, non-commercial consumption guidance committee should be set to periodically or a periodically publish consumption trend assessment report and forecast report, and guidance of how to consume scientifically and reasonably, so as to minimize abnormal consuming behavior caused by rational deficiency. The government should directly and strongly intervene into some abnormal consuming behavior (such as "white" consumption, pernicious consumption, conspicuous consumption) by economic means and legal means such as levying heavy tax and restraining consumption behavior by law. The media should be conscious of and shoulder their social responsibilities, and not hype those abnormal consuming behaviors. We should educate people to consume according to their purchasing power, their characteristics, their personality, and especially the rationality.

\section{References}

[1] Wu Xingyuan, Li Hui. Enrich Fromm_— A Blessed Life is One Filled with Love [M]. Beijing: New Word Press, 2006: 98

[2] People’s Daily: “Materialism” make moral and idea wither away. June 19, 2012.

[3] [Switzerland] Carl · Gustav · Jung. Translated by Guan Qunde. Mental Structure and Psychodynamics, International Cultural Publishing Company, 2011.

[4] [France] Jean Baudrillard. Consumer Society [M], translated by Liu Chengfu, Quan Zhigang. Nanjing: Press of Nanjing University, 2006: 18- 97.

[5] [U.S.] Enrich Fromm. The Sane Society [M], translated by Sun Kaixiang. Guiyang: Guizhou People Press, 1994: 134.

[6] Jean Baudrillard: Consumer Society, translated by Liu Chengfu, Quan Zhigang. Press of Nanjing University, 2000: 28 